\title{
Application of HF Radar in Hazard Management
}

\author{
Mal Heron, ${ }^{1}$ Roberto Gomez, ${ }^{2}$ Bernd Weber, ${ }^{3}$ Anna Dzvonkovskaya, ${ }^{2}$ Thomas Helzel, ${ }^{2}$ \\ Nicolas Thomas, ${ }^{4}$ and Lucy Wyatt ${ }^{1,5}$ \\ ${ }^{1}$ James Cook University, Townsville, QLD, Australia \\ ${ }^{2}$ Helzel Messtechnik GmbH, Kaltenkirchen, Germany \\ ${ }^{3}$ gempa GmbH, Potsdam, Germany \\ ${ }^{4}$ ACTIMAR, Brest, France \\ ${ }^{5}$ University of Sheffield, Sheffield, UK
}

Correspondence should be addressed to Mal Heron; mal.heron@ieee.org

Received 10 June 2016; Accepted 28 August 2016

Academic Editor: Weimin Huang

Copyright (C) $2016 \mathrm{Mal}$ Heron et al. This is an open access article distributed under the Creative Commons Attribution License, which permits unrestricted use, distribution, and reproduction in any medium, provided the original work is properly cited.

A review is given of the impact that HF radars are having on the management of coastal hazards. Maps of surface currents can be produced every 10-20 minutes which, in real time, improve navigation safety in restricted areas commonly found near ports and harbours. The time sequence of surface current maps enables Lagrangian tracking of small parcels of surface water, which enables hazard mitigation in managing suspended sediments in dredging, in emergency situations where flotsam and other drifting items need to be found, and in pollution control. The surface current measurement capability is used to assist tsunami warnings as shown by the phased-array data from Chile following the Great Tohoku Earthquake in 2011. The newly launched Tsunami Warning Center in Oman includes a network of phased-array HF radars to provide real-time tsunami monitoring. Wind direction maps can be used to locate the position of cold fronts in the open ocean and to monitor the timing and strength of sea-breeze fronts in key locations.

\section{Introduction}

Most HF radars that have been installed over the past 20 years have been predominantly for research and development. During this period the technology has become widely accepted as a significant tool in the research and management of the coastal environment. As a result we are now in a new era in which HF radars are being installed primarily for operational management and also for hazard warning and mitigation. HF radars are capable of mapping currents over large coastal areas (up to $200 \mathrm{~km}$ ) on a fine grid (down to $1 \mathrm{~km}$ ) as shown by Shay et al. [1] and Mao and Luick [2]. The primary parameter that HF radars measure is the surface current, with the effective depth of measurement being $\delta=$ $c /(8 \pi f)$, where $c$ is the electromagnetic phase speed and $f$ is the radar frequency (Stewart and Joy [3]). For a $16 \mathrm{MHz}$ radar $\delta$ is $0.75 \mathrm{~m}$. At this depth the currents are driven by winds and tides as well as the underlying large-scale circulation. It is this capacity to map the surface layer over a wide area in real time that makes the technology particularly well suited to hazard mitigation. In addition to surface currents, the phased-array genre of HF radar has the capacity to map significant wave heights on a grid over an area (Essen et al. [4]), and wind directions can be monitored on a spatial grid. In this paper the discussion focusses on WERA phased-array radar systems. Other systems have different levels of errors, resolution and accuracy, and perform rather differently in hazard management.

Real-time quality control is essential for operational data, and Section 2 discusses some of the procedures used for HF radar surface current data.

With surface currents on a fine spatial grid, repeating on a short time lapse, it is useful to calculate the Lagrangian tracks that floating objects would follow, provided that special care is taken to assure the quality of the data described by Mantovanelli et al. [5]. Phased-array HF radar technology has the comparative advantage of high resolution and accuracy that are needed for Lagrangian tracking. This has applications in pollution control, salvage, and search-and-rescue operations and is demonstrated in Section 3 of this paper. 
Tsunamis are shallow water gravity waves, even in the deepest oceans. In deep ocean water they are undetectable with HF radar because their amplitudes are small and their wavelengths are long $(>100 \mathrm{~km})$. However, in shallow water on the continental shelf, the signatures of the tsunami are amplified and it has been shown that HF radar can detect the surge currents of the orbiting surface particles as the tsunami wave train passes a point (Heron et al. [6]). HF radars are now being installed specifically to monitor the coastal ocean for approaching tsunamis, and Section 4 shows how this is being done in Oman.

The capacity to plot maps of surface wind directions is being evaluated to feed in to the forecasting of the movement of cold fronts in the southern ocean in the Great Australian Bight. This is an area of sparse weather stations in a place where the movement of cold fronts is a key parameter, particularly in the management of bush fires in South Australia and Victoria. This is discussed in Section 5 of the paper.

An example of the use of HF radar in routine management of a busy port is given in Section 6, using data from the WERA radar installed at the Port of Rotterdam in Netherlands (Van Heteren et al. [7]). These initiatives in Europe as well as developments like The US Ports Infrastructure Projects recognise the need for operational use of current monitoring around ports. The dual-purpose use of HF radar for emergency as well as routine management was illustrated by its notable absence in the demise of the MV Rena off Tauranga in New Zealand in 2011.

\section{Real-Time Quality Control for Hazard Management}

Ocean surface data provided by HF radar show sporadically nonrealistic values in some areas, particularly at the outer edges of the radar coverage, which do not correspond to the measured phenomena. Some reasons for the appearance of such measurements are radio frequency interference, lightning, ionosphere clutter, and ship echoes. Several techniques have been developed for phased-array type HF radars to mitigate (Gurgel et al. [8]) or to overcome (Heron and Prytz [9]) such disturbances in the data, drastically reducing their appearance. Despite such efforts, it is impossible to avoid some poor quality data in the output from the radar system. Additionally, limitations which are inherent to the system itself such as the geometric arrangement when combining data sets of radial components, azimuthal resolution at far ranges, and signal-to-noise variation between day and night may degrade the accuracy of measured data.

For hazard applications, the reliability of the data is essential and quality control criteria need to be set at appropriate levels. Furthermore, in cases of time-sensitive applications (like tsunami detection or forecast for search-and-rescue and oil spill scenarios) QC needs to be performed immediately on each data set as it becomes available (near real-time).

To cover this need for QC, the WERA HF radar system includes QC routines which are integrated into the data processing chain and applied in near real-time. The QC processing parameters can be tuned to the specific dynamic characteristics of the ocean being measured for optimal performance.

Although most applications require the horizontal and vertical components of the current velocity, the WERA QC procedure focusses on the step immediately preceding that and is applied to each radial component value on the common and predefined Cartesian grid. This has the advantage of dealing with data at the earliest point before any averaging or combining of data from two stations to form the surface current vectors on the Cartesian grid. The procedure consists of performing a series of tests on measurements in each grid cell in the latest radial current dataset obtained. The tests evaluate the measurements and analyze their consistency with past measured values. At the end, each grid cell will be given a quality level number from 1 to 5 , where quality level 1 is the best quality and quality levels 4 and 5 are considered to be corrupted data. The processing chain may automatically exploit this option to obtain cleaner current velocity vector maps in eastward and northward components by combining radial velocities from two or more radars in which undesired quality levels are omitted.

It is important to note that no data are deleted during the QC procedure. The data points are just individually marked with a quality level.

Similar methodologies are applied to wave data and wind direction data provided by the WERA system.

2.1. Case Study: QC at South Florida. As reported by Gomez et al. [10], the QC procedure was implemented on the current velocities measured by a pair of WERA HF radar systems of the University of South Florida (labelled in Figure 1 as Ft DeSoto and Venice) and tested for a period of 9 months. The QC parameters used in this experiment were empirically tuned using data for one month from both stations. The performance of the QC procedure was evaluated by comparing the data from Venice station with the radial projection of the current velocity measured every hour by an Acoustic Doppler Current Profiler (the red dot in Figure 1 labelled as C10) and calculating a correlation coefficient. The correlation coefficients of radar data compared to ADCP data were obtained excluding different levels of quality. The results are shown in Table 1.

It can be observed that data which are identified by the WERA QC process to be corrupted represent a very small percentage of the total data and indeed as a separate group show a very poor agreement with the ADCP. Excluding these low-quality data from the data set produces an overall improvement of the correlation coefficient. Furthermore, different levels of quality effectively classify different levels of reliability in the measured data.

2.2. Improve Reliability of Metocean Warnings. The data provided by an HF radar may be used by port authorities or civil-protection as an additional complementary source of information when deciding upon metocean warnings. Such an application is a clear example that requires both real-time access and reliability on the data. 


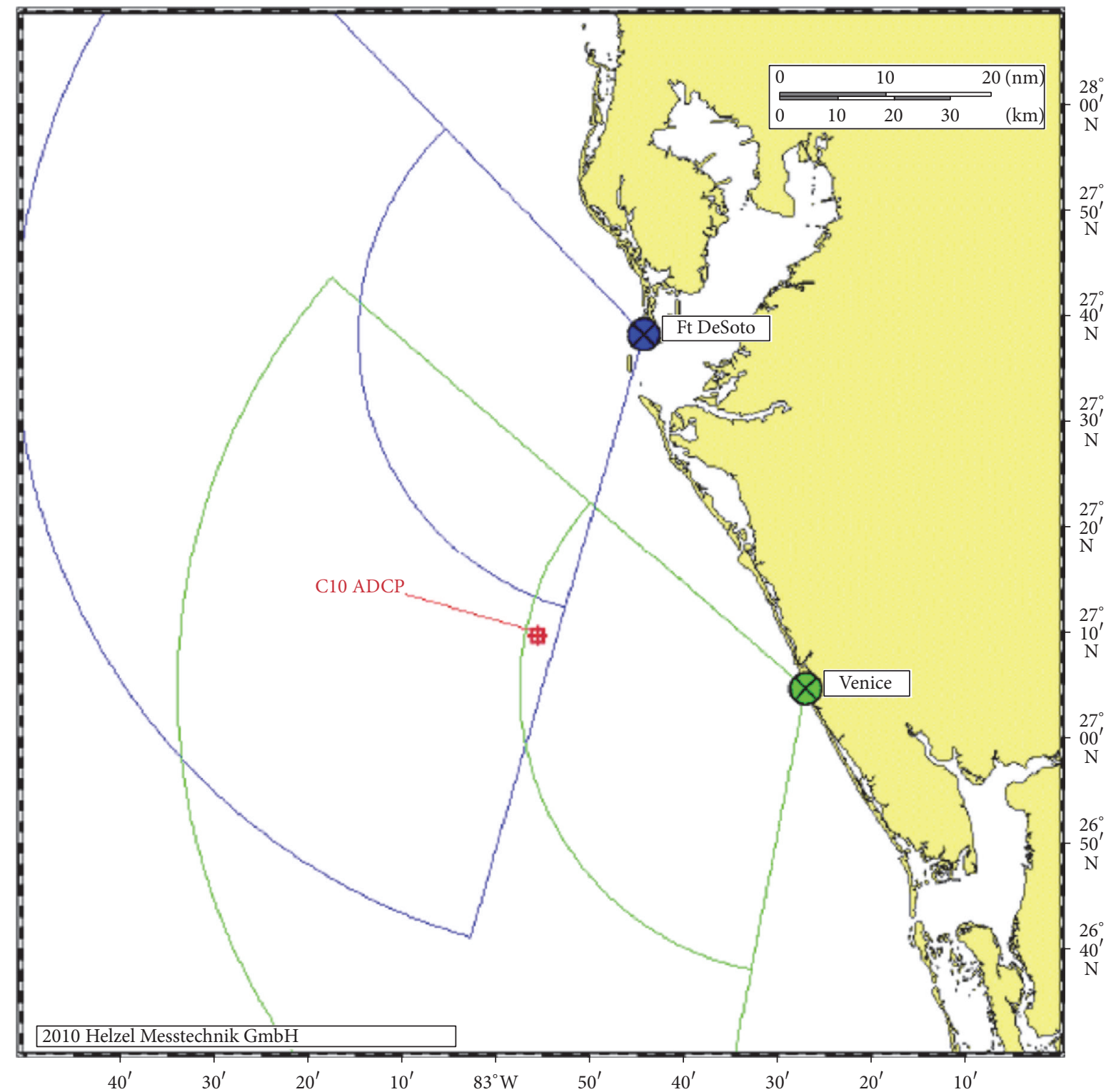

FIGURE 1: Position and range of WERA systems and ADCP location used for the case study in South Florida.

TABLE 1: Correlation coefficients for different quality levels of data provided by Venice site at the location of ADCP.

\begin{tabular}{lcc}
\hline Condition to satisfy to be included in correlation calculation & Number of data points & Correlation coeff. $(R)$ \\
\hline All data available & $2316(100 \%)$ & 0.87 \\
Quality level $>3$ (corrupted data only) & $28(1.2 \%)$ & 0.44 \\
Quality level $\leq 3$ (all valid meas.) & $2288(98.8 \%)$ & 0.90 \\
Quality level $=3$ (deficient but still ok) & $171(7.4 \%)$ & 0.68 \\
Quality level $=$ 2 (medium quality) & $495(21.4 \%)$ & 0.83 \\
Quality level $=1$ (best quality) & $1622(70 \%)$ & 0.93 \\
\hline
\end{tabular}

A straight forward application of HF radar data for metocean warnings is to search for high values of current or wave height measured at the last data set available from the radar. The search could be either at predefined critical points in the ocean (port entrance) or at the whole monitored area. If the measured parameters exceed a certain threshold, an automatic warning notification can be sent. However, if the data sporadically show spikes of corrupted data, there is a high risk of registering false warnings.

One way to reduce the occurrence of false warnings is to apply spatial averaging which can potentially mitigate the effects of a local spike. This is the least satisfactory approach 


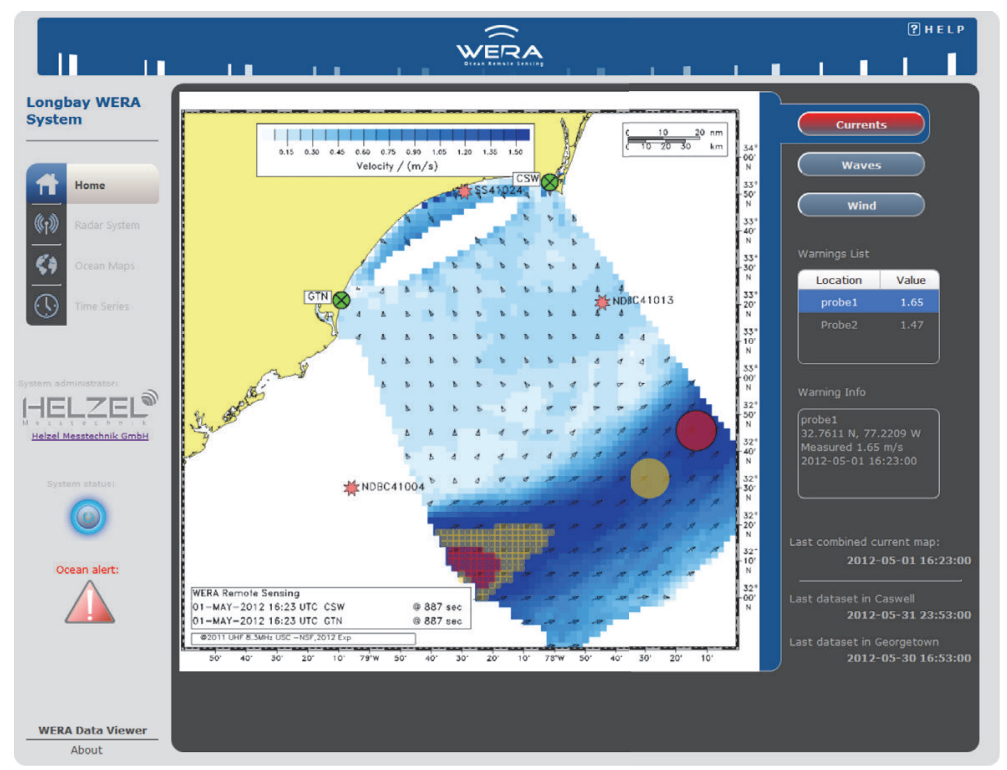

FIGURE 2: Ocean warning displayed on the WERA Data Viewer web interface. Coloured circles correspond to warnings on specific locations being monitored; small squares correspond to areas where global thresholds set on the whole coverage area have been exceeded. Yellow zone represents a low risk warning and red zone represents a high risk warning. To avoid congestion, current direction arrow is shown at every 5th grid cell.

because contaminated data become woven into the final result in the process of averaging. In the case of artefacts which are spatially spread (e.g., radio frequency interference) or in the case of highly dynamic seas a simple average is particularly unreliable. Applying QC to the data in near real time before searching for spikes and artefacts may eliminate or highly reduce the risk of false warnings. To further increase the level of confidence, the use of HF radar data for critical decisions may be limited to data with a certain level of reliability (i.e., quality levels 2 and 1 when using the flags adopted by the WERA QC procedure).

Figure 2 shows a screenshot of the WERA Ocean Warning add-on feature in the Data Viewer web interface of WERA. The software can be configured to ignore data values that do not fulfil a certain level of quality, size-configurable spatial averaging, and two different threshold levels (for high and low risk) for specific coordinates or for the whole covered area. Warnings are automatically send to competent authorities or decision makers via email.

\section{Lagrangian Tracking of Surface Drifters and Short-Term Forecasting}

The availability of gridded current data at short return periods of less than one hour invites the calculation of Lagrangian tracks and short-term forecasting. With the availability of surface currents on a fine spatial grid, repeating at short time intervals, the empirical Lagrangian tracking method uses water velocity at one point in time and space to step forward one time increment to a new position. These products are derived after a special QC process by analyzing the different physical drivers of surface currents and processing each of the driving effects to improve quality and make interpolations and extrapolations as required.

3.1. Lagrangian Tracking. At any time and location the current can be derived and applied to a notional parcel of surface water which is projected on to a new location after one time step. At the new location the current velocity is interpolated and another step is taken and so on. Mathematically, this is risky because it is an integration process where errors are cumulative and can become quite large. This is why some authors use surface drifters to validate $\mathrm{HF}$ radar surface currents, measure the drifter displacement over a short time interval to calculate current velocity, and compare that with the radar currents (Ohlmann et al. [11]). This removes the integration problem but is no good for tracking drifting particles. While many HF radar installations can forecast a general direction for Lagrangian drifters (Ullman et al. [12]), a phased-array radar with careful quality control on the realtime data is shown to produce tracks that are within a few kilometres of the true position over many tidal cycles.

In practice special QC processing is required, even with good quality WERA data because Lagrangian tracking requires a filled spatial grid and filled time series. This means that data values that have a low QC flag have to be replaced as accurately as possible to maintain the accuracy of the Lagrangian tracking. It is clear in Figure 3(a) that the biggest rates of change are derived from the tidal component of the current. There are two points to note about this: one is that it is difficult to identify "spikes" in the data and the second is that the tidal component of the current is predictable. We carry out a tidal analysis to get the tidal constituents over the last 30-day period and remove the tidal signal from the 


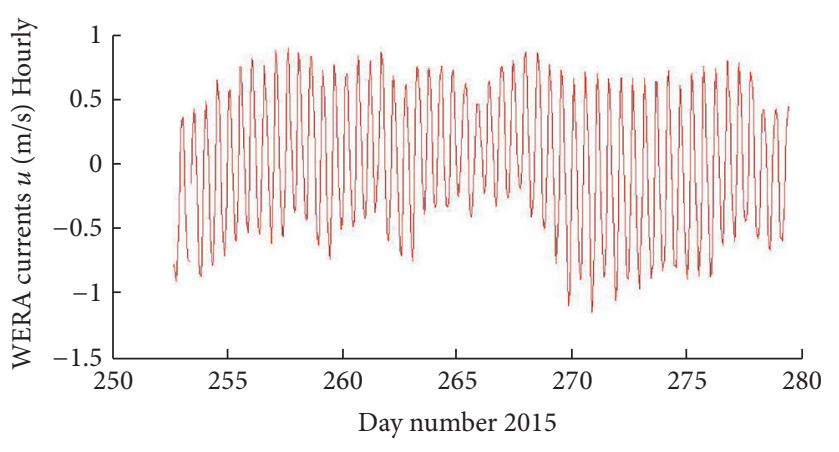

(a)

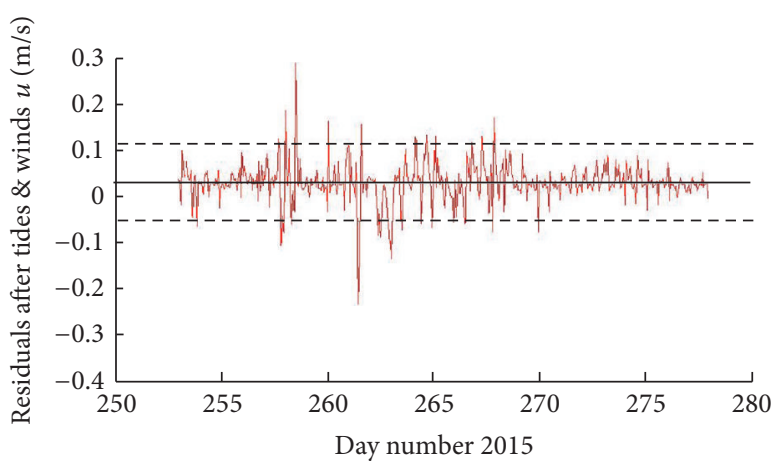

(b)

FIgURE 3: A time series of WERA $u$-component (a) with residuals after tidal and wind-driven $u$-components are removed (b). The horizontal black dash lines indicate \pm 2 standard deviations. Data points in the residual outside these lines are replaced by interpolation in the residual time series. The WERA $u$-component of current is then reconstructed by adding wind-driven and tidal $u$-components. The data shown are from a site near Rotterdam in the North Sea.

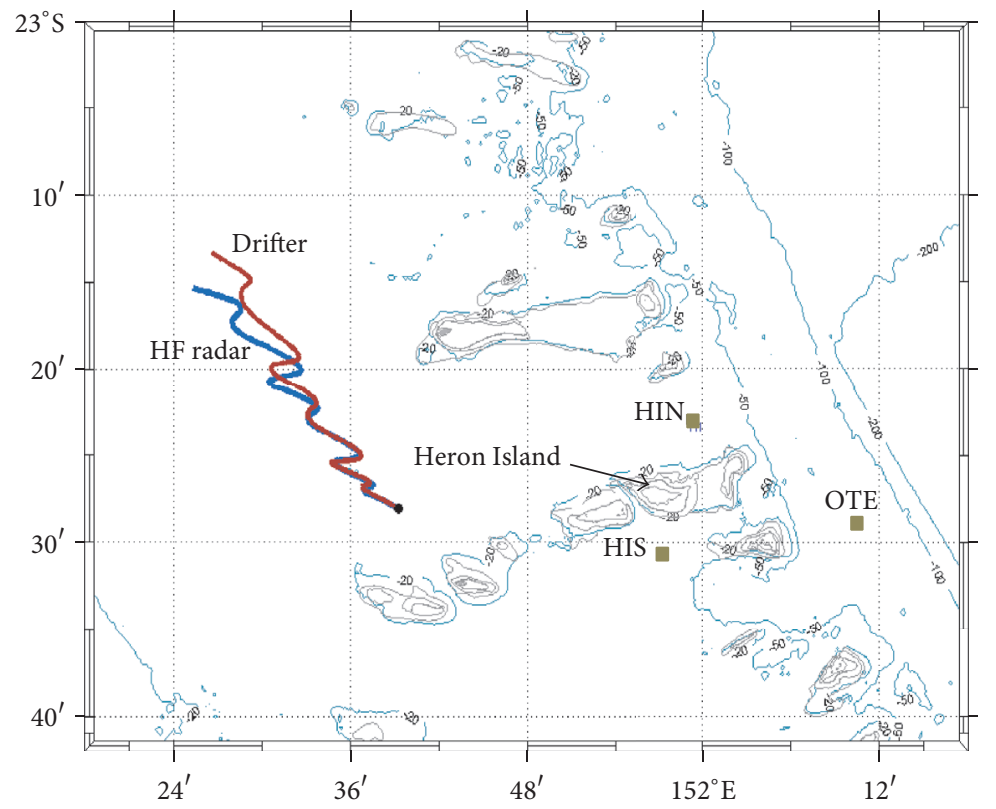

FIGURE 4: A surface drifter tracked by satellite follows the red line, while a track derived from HF radar data using the same starting location and time follows the blue line. The zigzags are due to the dominant 12-hour tide, and the trend towards the northwest is due to the synoptic surface wind. The site is on the Great Barrier Reef, Australia.

radar time series. If there are reliable wind data then a fitted wind-driven current may also be removed. The residual thus produced (Figure 3(b)) is smaller in amplitude and spikes can be identified. The rms of the residual is calculated, and any point that exceeds $2 \mathrm{x}$ rms is removed and replaced by a value that is interpolated in the time/space domain at the residual level. This process is repeated until it stabilises and then the tidal component is added back into the time series. The strength of this method is that we are interpolating only that part of the signal that has unknown driving forces (e.g., wind, diffusion, and mesoscale currents) (Mantovanelli et al. [5]), and we are accurately calculating the value of the tidal current. When the spikes are removed the interpolation is only in the residual signal where errors in interpolation are reduced. The final step is to reconstruct the surface current vector by adding the tidal and wind-driven components to the amended residual time series.

An example of this procedure is shown in Figure 4 which depicts a section of area covered for surface current mapping by WERA HF radar stations located at Tannum Sands and Lady Elliot Island in the southern Great Barrier Reef region. The radar operated at $8.38 \mathrm{HMz}$ with a $50 \mathrm{KHz}$ bandwidth. A surface drifter with a GPS receiver and satellite communications link was released at the black dot. A feature of interest in the data in Figure 4 is the abrupt separation of the tracks after about 36 hours (zigzags are tidally driven and occur at 12 hour intervals). Prior to that event, the tracks are very close (inseparable on the diagram), and afterwards 


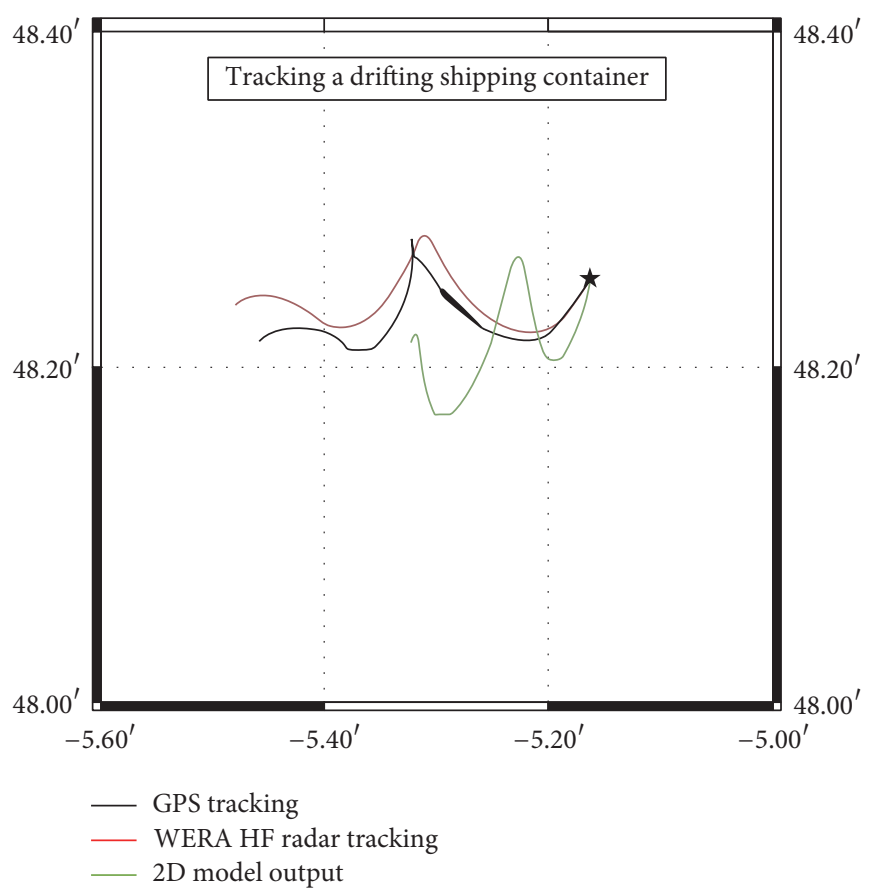

FIgURE 5: Tracking a drifting shipping container in the Iroise Sea. The HF radar Lagrangian tracking position is about $5 \mathrm{~km}$ off the actual position after 18 hours. The fluctuations in the tracks are due to the semidiurnal tides.

there is a steadily increasing separation. This phenomenon is repeated when we consider two closely spaced drifters (Mantovanelli et al. [13]) or alternatively two radar tracked points which start closely spaced. This is the focus of ongoing research because there is a feature in time or space that causes a dramatic change in the horizontal diffusivity at the surface that has similar characteristics to Lagrangian Coherent Structures (LCS) described by Shadden et al., [14].

An independent example of successful Lagrangian tracking is shown in Figure 5 in the Iroise Sea using a WERA radar system operating at $12.38 \mathrm{MHz}$ and bandwidth of $100 \mathrm{KHz}$ by ACTIMAR on the west coast of Bretagne (Helzel et al. [15]). A drifting shipping container followed the track drawn in black for approximately 18 hours, while the radar-based track is shown in red. The effective depth of tracking for the radar at $12.38 \mathrm{MHz}$ is $0.97 \mathrm{~m}$.

These examples show that WERA HF radar produces Lagrangian tracks that are based on real data and have none of the assumptions of diffusion coefficients, wind effects, or other parameterisations that exist in hydrodynamic models. With the precautions discussed, particles have been tracked on the shelf for up to 4 days (with errors typically $2-4 \mathrm{~km}$ per day). The research applications of these techniques include spatial and temporal changes in diffusivity and larval connectivity between reefs. There are obvious applications in searchand-rescue, pollution management, and port management.

3.2. Short-Term Forecasting. Statistical forecasting of the surface current fields is one of the possibilities offered by ocean surface radars. Statistical forecasting means predicting the future based on past data and using only statistical algorithms, without any physical model. It must be distinguished from physical forecasting which uses dynamic equations to propagate data from the past, for instance, with an ocean model and its initial conditions.

Since HF radar currents can cover a significant coastal area with a good spatial resolution and a high temporal resolution, the signature of most of the local ocean physical processes that contribute to the evolution of surface currents can be captured. If processes are well captured and the system is predictable, statistical algorithms are able to extrapolate currents into the near future (24-48 h) after a learning phase.

A statistical forecast solution for the surface currents based on a space-time EOF analysis was developed and integrated into the commercial tool CurExtrap@ $@$. An example of CurExtrap $\odot$ output is presented in Figure 6. Obviously, the quality of the forecast produced relies on the quality of the input measurements and on the possibility to assess the effective quality of the input data during the statistical analysis.

\section{HF Ocean Radar Support for Tsunami Early Warning Systems}

4.1. Observations of Tsunamis by Phased-Array HF Radar. A tsunami is a series of waves that can be generated when earth plate boundaries abruptly move and vertically displace the overlying water. Although a tsunami cannot be prevented, the impact of a tsunami can be mitigated through community preparedness, timely warnings, and effective response. 


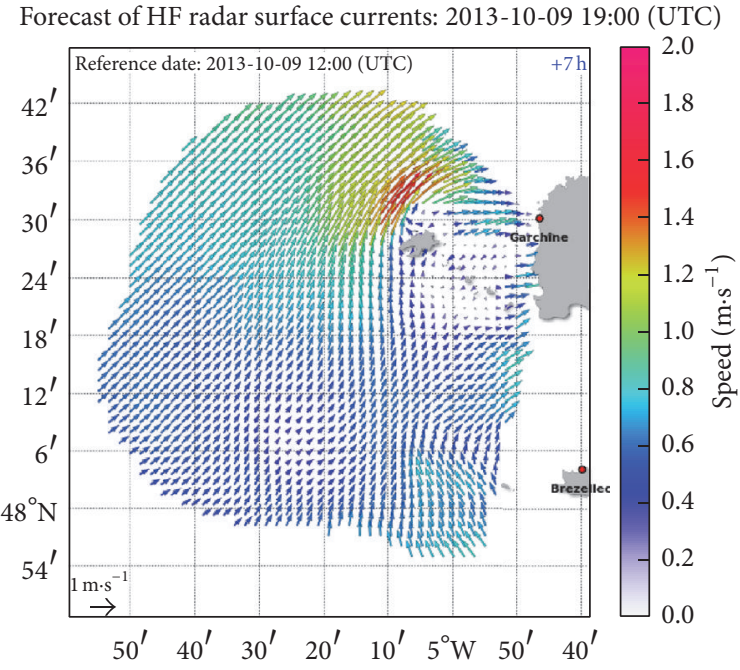

(a)

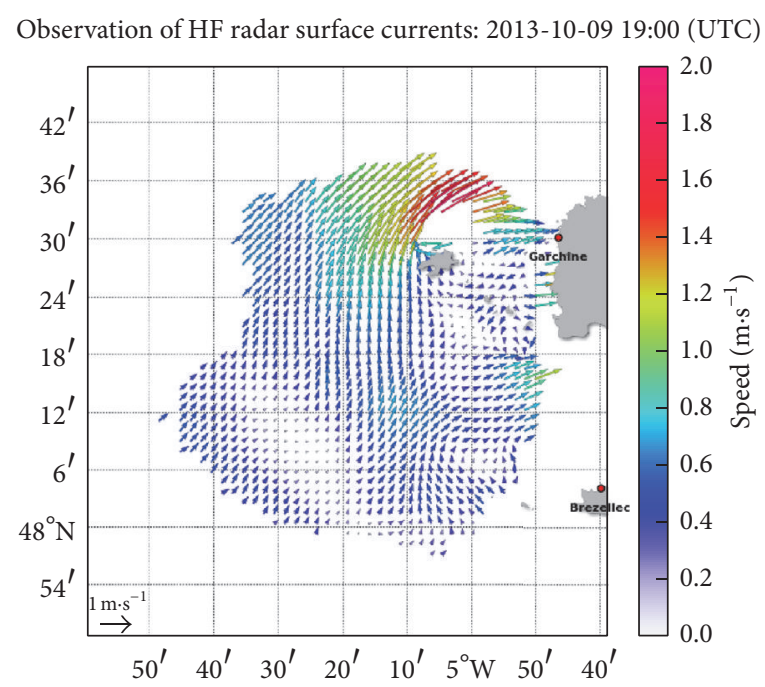

(b)

FIGURE 6: Example of a forecast of surface currents with CurExtrap in a tidal environment observed by 2 WERA radars, in Iroise Sea, France. (a) Statistical forecast made at $1200 \mathrm{~h}$ UTC. (b) Validation of the forecast by the radar measurements 7 hours later at $1900 \mathrm{~h}$ UTC. Radar data source: SHOM (Service Hydrographique et Océanographique de la Marine); figures provided by ACTIMAR.

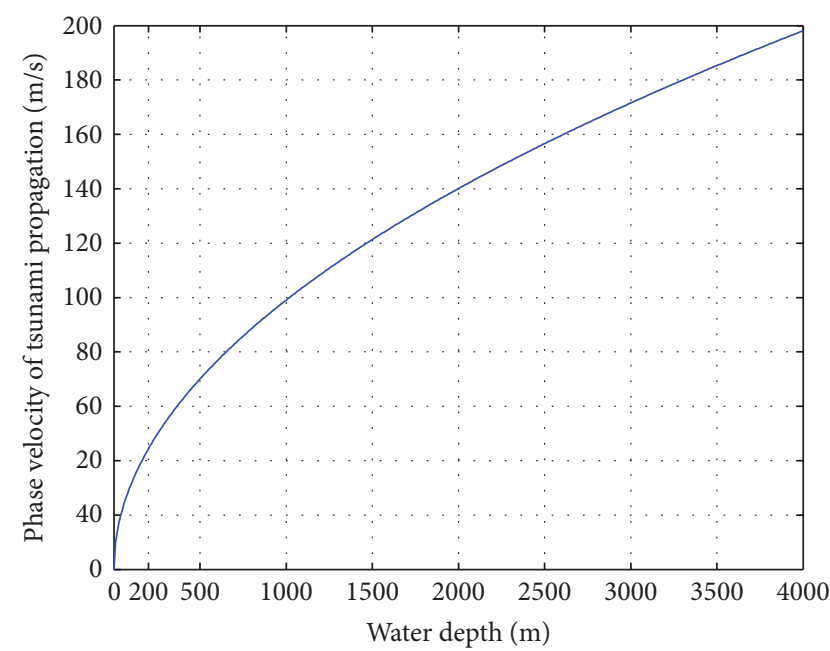

(a)

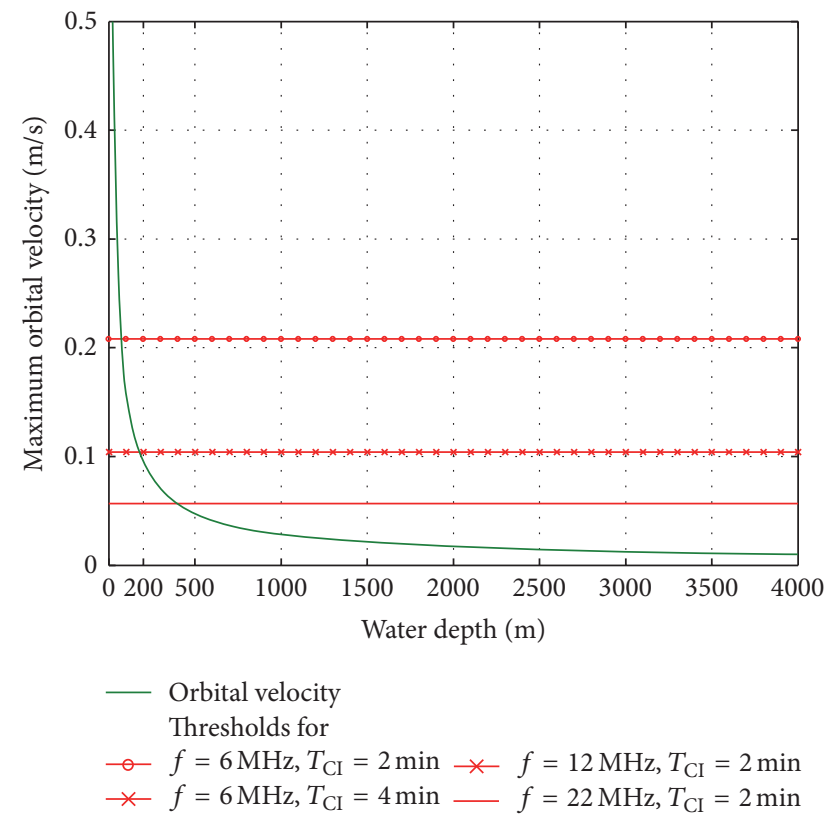

(b)

Figure 7: Linear theory results. (a) Tsunami phase velocity of propagation as a function of water depth; (b) the maximum horizontal velocity (surface current velocity) of orbiting surface particles in a tsunami wave (green line) and lower boundaries for tsunami detection by phasedarray HF radar (red lines).

Tsunami Early Warning Systems (TEWS) meet the challenge of near field warning with extremely short warning time. When tsunamigenic earthquakes have epicentres close to the shore, the time between a seismic event and the issue of a warning may be limited to just a few minutes.

When tsunami disturbances propagate in the deep ocean as shallow water gravity waves with zero dispersion the phase velocity can be approximated by linear wave theory as $c=\sqrt{g d}$, where $g$ is the gravity acceleration and $d$ is the water depth. The phase velocity dependency is shown in Figure 7(a). As the tsunami approaches the coast and the waters become shallow, the wave is compressed due to wave shoaling and its speed slows down to $20 \mathrm{~m} / \mathrm{s}$. Its wavelength typically diminishes to less than $20 \mathrm{~km}$ and its amplitude 
grows enormously, producing a distinctly visible wave as described by Green's Law (Green [16]).

The orbital motions of surface particles, as the shallow water gravity wave propagates past a point, are horizontally elongated ellipses with the semiminor axis (water elevation) given by Kinsman [17]. The application of linear theory for the maximum orbital velocity (surface current velocity) as a function of depth is given by $v_{m}=a(d) \sqrt{g / d}$, where $a(d)$ is the tsunami wave amplitude in water of depth $d$ and $g$ is gravitational acceleration. This is illustrated by the green lines in Figure 7(b) for a tsunami wave with an initial elevation of $0.2 \mathrm{~m}$ in a deep ocean. It can be easily seen that surface current velocities induced by a tsunami are many orders of magnitude smaller than the phase velocity of tsunami propagation. Nevertheless, these current velocities can be accurately measured with high spatial and temporal resolution using the phasedarray $\mathrm{HF}$ ocean radar technology. The sensitivity of the radar in resolving the surface current velocities strictly depends on the operating radar frequency $f$ and integration time $T_{\mathrm{CI}}$ as shown in Figure 7(b) by red dashed lines. These lines are velocity resolution thresholds derived from radar characteristics. All tsunami current velocities with values above these thresholds have a chance to be detected offshore. While the tsunami wave is approaching the continental shelf, the surface current pattern changes from small magnitudes in deep water to more significant values in the shelf area as shown by Gurgel et al. [18]. This strong change of the surface current can be detected by a WERA system in realtime monitoring. The fact gives an opportunity to issue an automated tsunami watch message by the WERA radars to TEWS. The detection with a WERA radar system will be in the vicinity of $300 \mathrm{~m}$ depth depending on the magnitude of the tsunami. For a shelf of average depth $50 \mathrm{~m}$ and width $100 \mathrm{~km}$ the warning time before the tsunami impacts the coast will be about 75 minutes. Hence by measuring the surface current velocities, HF ocean radars are able to contribute to the development and improvement of TEWS. If these radar systems have been already installed at the coast then their upgrade for tsunami observation is easy and inexpensive.

Observations of tsunamis by HF radar are sparse, but a case presented itself on March 11, 2011. One WERA HF radar station was in operation when the Great Tohuku Earthquake in Japan produced tsunami waves that hit the Chilean coast after 22 hours of propagation across the Pacific Ocean. The radar was located near Rumena, Chile, and supplied ocean surface monitoring in that region. The radar measurements at $22-\mathrm{MHz}$ frequency were recorded and archived for several hours while the tsunami wave train was impacting the Chilean coast.

The radial velocities of ocean surface currents were estimated from the radar spectra. To obtain the pure tsunamiinduced currents, a filtering technique was applied to eliminate the natural surface current field, which included tidal components. The velocity measurements were achieving accuracy of a few $\mathrm{cm} / \mathrm{s}$, which means that the sensitivity of radar measurements was good enough to catch the small changes caused by the tsunami in deep water. Moreover, it can be clearly seen that the tsunami current velocity became higher as the wave entered the shelf area. This fact is in line with the model assumptions in (Gurgel et al. [18]). Although the shelf width is only $10-20 \mathrm{~km}$, a slight inclination in range of the measured currents shows that tsunami waves crossed the shelf within a few minutes.

The estimated tsunami wave periods were in the range 14-32 minutes. This suggests that any potential tsunami monitoring by ocean radar requires a continuous operation mode with a fast update of about 2 minutes for the ocean surface current measurements.

The HF ocean radar does not measure the approaching wave front (wave height) of a tsunami; however, it can detect the surface current velocity signature, which is generated when tsunami reaches the shelf edge. The HF ocean radar could provide valuable information to increase the reliability of TEWS under fulfilment of certain conditions:

(i) The ocean bathymetry within the radar coverage is to be known in sufficient detail to plan an ocean radar installation with maximum effectiveness for tsunami monitoring.

(ii) The spatial radar resolution must be sufficient to resolve the current signature. It is necessary for the radar system to achieve high signal-to-noise performance and narrow beam directivity. These features can be obtained using an array type WERA system with multiple channels and a beamforming technique.

(iii) The temporal resolution of the radar must be high enough to pick up the fast changing surface velocity vectors. The potential tsunami areas should be monitored in a fast acquisition mode, which provides a quick update of the ocean surface current fields, for example, at a 2-minute rate. Based on this mode, an algorithm to detect a tsunami signature in the HF radar data is developed.

The output data of WERA processing software can be easily integrated into existing TEWS due to flexible data format, fast update rate, and quality control of measurements as well as be a part of systems, which provide simulation and assimilation for different tsunami scenarios. The data can be also archived for further hazard analysis and research purposes.

4.2. Case Study: Operational Tsunami Warning System in Oman. The newly launched Tsunami Warning Center in Oman is one of the most sophisticated tsunami warning system worldwide applying a mix of well proven state-of-theart subsystems while otherwise applying newest technologies. It serves as a benchmark for the integration of HF radar data into the tsunami warning procedure.

The core of the tsunami warning system is the seismic real-time analysis system SeisComp3 described by Hanka et al. [19] and used in most tsunami warning centers globally. The tsunami simulation and decision support system is based on the Tsunami Observation and Simulation Terminal (TOAST) system developed by gempa $\mathrm{GmbH}$, which integrates a precalculated tsunami scenario database and a GPUbased based "on the fly" simulation allowing the system to react to atypical earthquakes that are not considered by the 


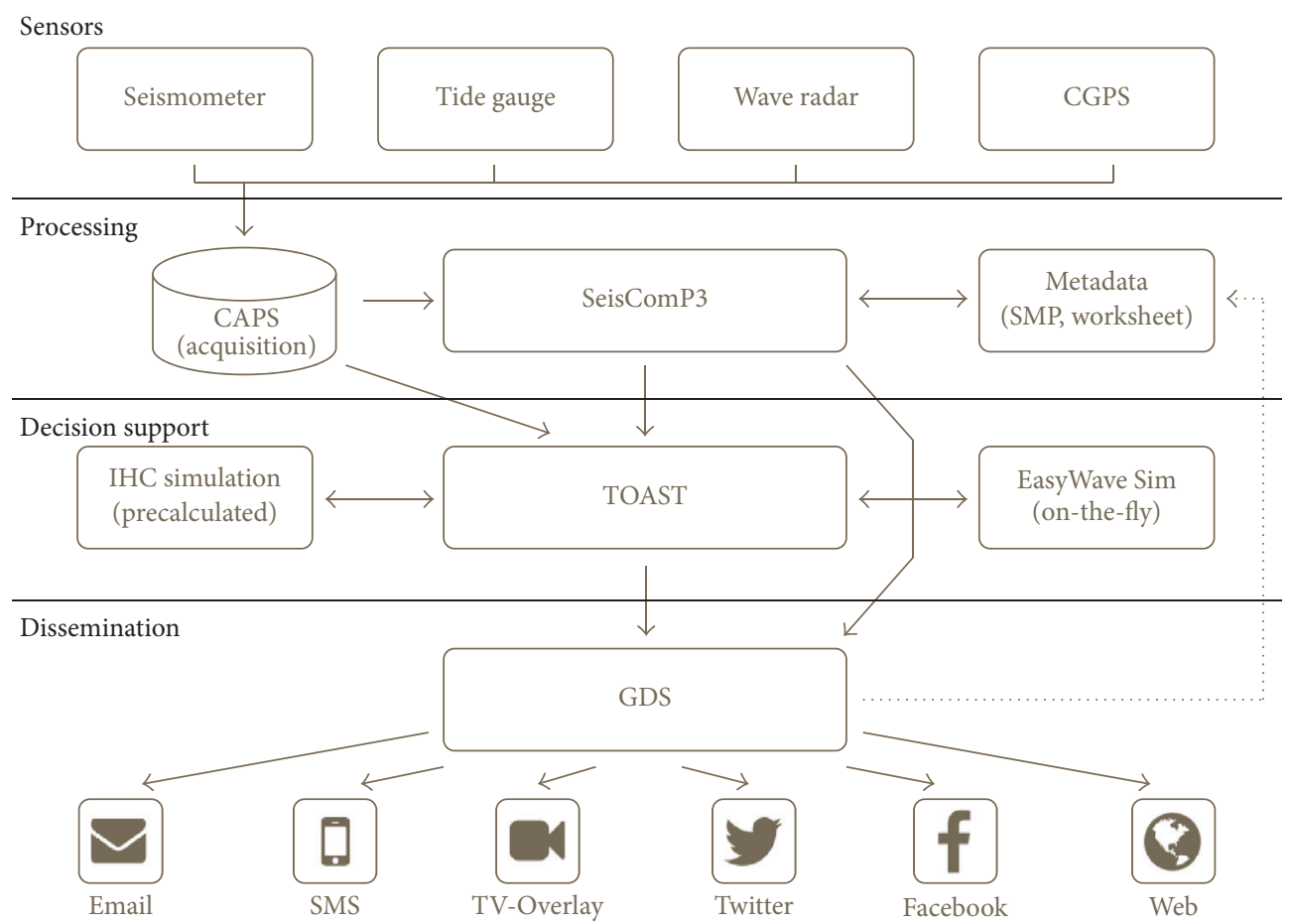

FIGURE 8: Architecture and data flow of the tsunami warning system in Oman processing seismic, tide gauge, wave radar, and cGPS data.

precalculated database. Simulations can be verified by the comparison of simulated and measured oceanographic data.

Most tsunami early warning centers employ tide gauges. Due to high costs, buoys are rare. The Omani TEWS also integrates measurements of a modern network of phasedarray HF radars to verify simulations in TOAST giving additional scenario quality information and confirmation to the decision support. The CAPS (Common Acquisition Protocol Server) developed by gempa $\mathrm{GmbH}$ greatly simplifies the integration of multisensor data in TOAST. CAPS allows the acquisition of data from many different sensor systems including seismic stations, GNSS, tide gauge, and HF radar in one acquisition system providing access to all sensor data through a common interface (Figure 8).

While tide gauge data are integrated as traditional time series (sometimes called mariograms), the radar tsunami data are integrated in TOAST as a chain of "virtual" oceanographic sensors located at the shelf edge. The data are displayed in form of velocity streams generated at the virtual sensors and are treated in a similar way to tide gauge or buoy data. HF radars measure surface orbital within the waves of passing tsunami wave-trains and can be used for picking the tsunami onset time (Figure 8, bottom) and can be used to confirm wave amplitudes using the linear transform given in Section 4.1 to calculate amplitude from the maximum velocity and water depth. These onsets can be used to verify arrival times of the simulated scenarios and give additional information about the exact location of the rupture area.

The wave radar allows offshore monitoring, providing valuable input to the tsunami verification. If the tsunami genesis is far distant, the SeisComP3 and TOAST systems will already be alerted and the $\mathrm{HF}$ radar data serve as confirmation of timing and severity of the hazard. When the tsunami genesis is close the HF radar data take a dominant role in the warning system. In some cases HF radar is used as an alternative to the expensive and maintenance-intense buoys.

\section{Maps of Surface Wind Fields}

The first-order Bragg lines in the spectra of beamforming phased-array HF ocean radar systems are echoes from two specific wind waves in the target cell of the radar. One of the Bragg lines is from the resonant wave approaching the radar station (line (a) in Figure 9) and the other is from the receding resonant wave (line (b) in Figure 9). Wind waves, at a given wavelength, have a directional spreading form that has a maximum in the direction of the wind and a near null in the up-wind direction.

By assuming a shape for this spreading, the wind direction can be derived by observing the ratio of Bragg peaks (a) and (b) illustrated in Figure 9 following Heron and Rose [20]. This is a closed form when data from two radar stations are used, and the wind directions can be calculated for each grid cell. Wyatt et al. [21] used a $3 \times 3$ set of pixels in a maximum likelihood method to extract the two parameters of wind direction and the directional spreading of the wind. These two parameters are shown in the case study of Figure 10 with the region of high directional spreading clearly marking the position of the front. Here the interpretation depends on the assumption that the wind direction is that of the dominant 


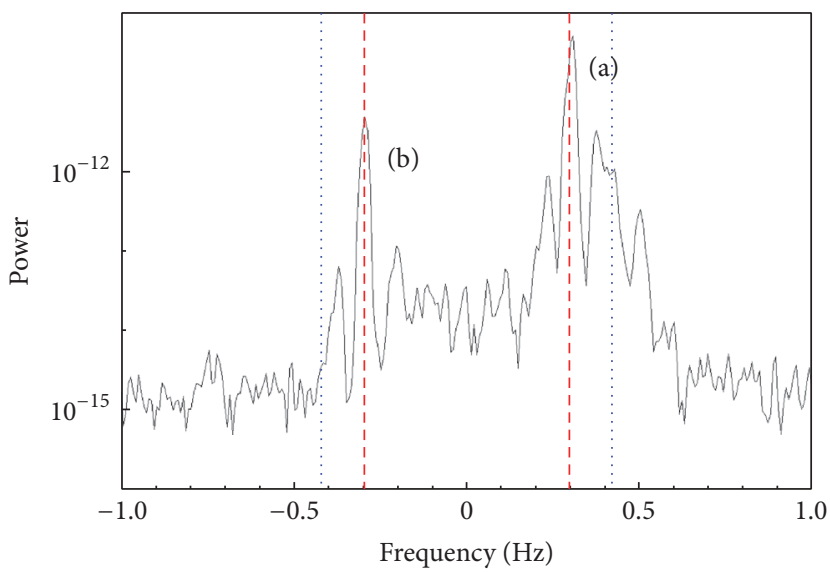

FIGURE 9: Spectra from phased-array radars are produced for each grid point, and the ratio of amplitudes of the sharp Bragg peaks (a and b) are used to estimate the direction of the wind.

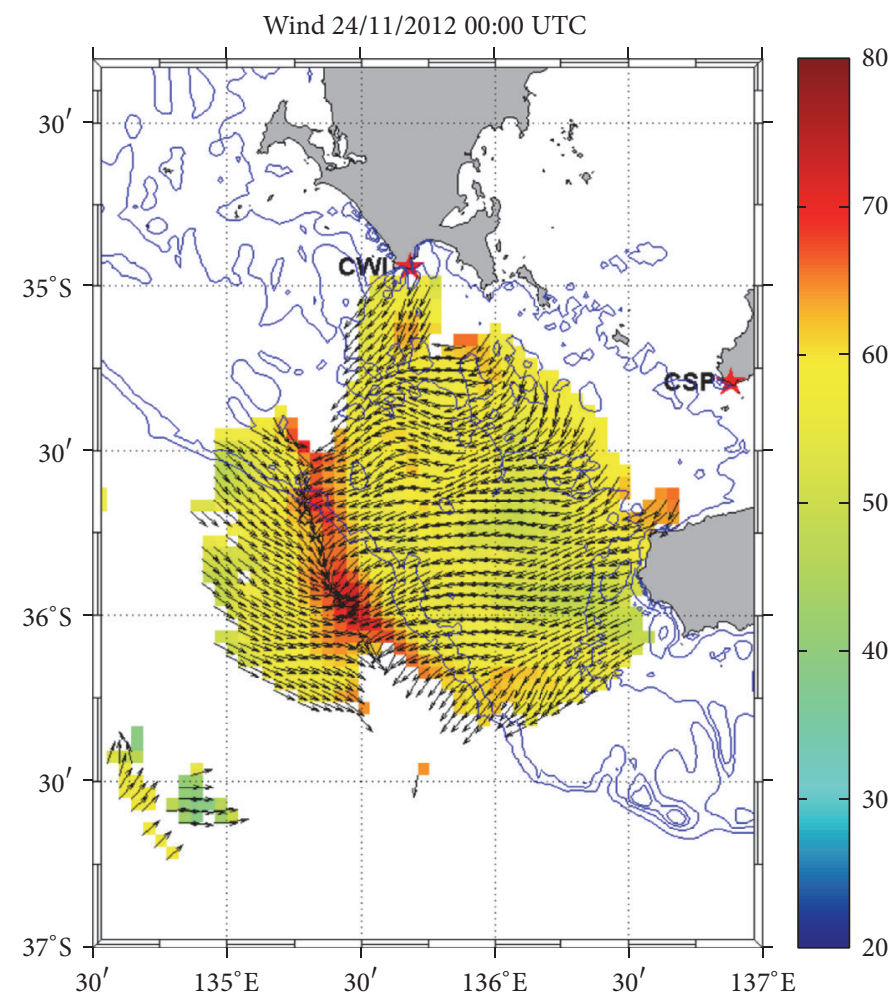

FIGURE 10: Data from the two radar stations (red stars at CWI and CSP) are combined at each grid point to calculate the wind direction shown by a field of arrows of equal length. The colour bar represents spread in the wind direction in degrees.

wind-wave direction. Wyatt [22] examined the accuracy of this assumption.

Maps of wind directions are particularly useful in the southern ocean where meteorological stations are sparse. The mapping of cold fronts moving across the area shown in Figure 10 off South Australia can be used to improve the forecasting of wind events in the eastern part of South Australia and in Victoria. In the summertime it is these frontal systems with high wind speeds and rapidly changing directions that exacerbate the hazard of bushfires. The timing of the arrival of the fronts is a key parameter for managing bush fires and is accurately determined from the HF radar monitoring.

\section{HF Radar in Port Management}

One of the hazards in the operation of coastal ports is the strength of the alongshore current at the seaward end of the breakwater or training walls so that the pilot can compensate and avoid grounding. Real-time surface current data in the 


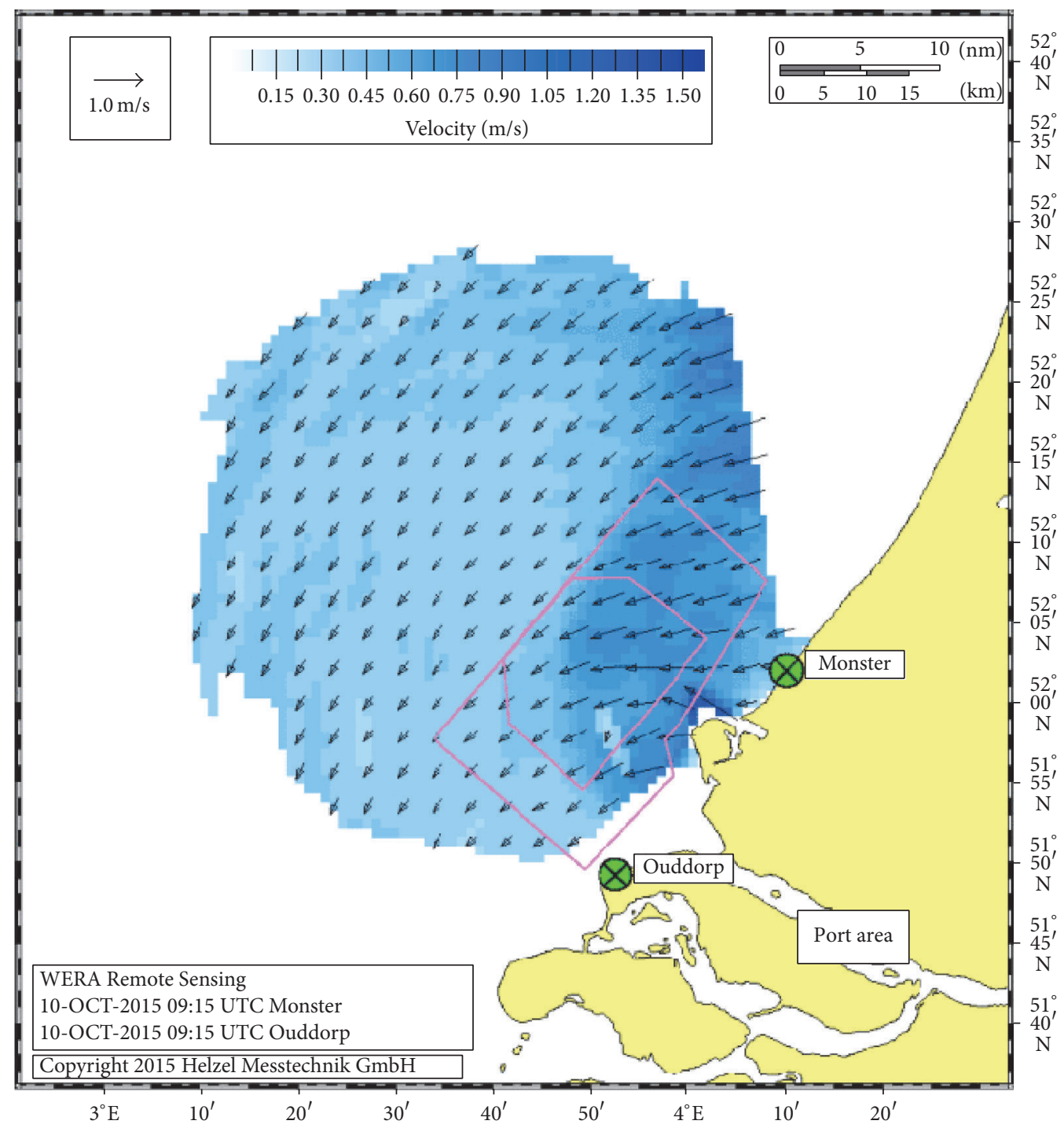

FIgURE 11: Typical output from the WERA radars at the Port of Rotterdam showing the radar station sites (green cross) and the main port area. The pink boxes indicate areas with different requirements on radar data availability in the real-time system.

outer port area can also be used to reduce hazards in the case of emergencies and for routine dredging operations.

\subsection{Case Study: Real-Time HF Radar Current Maps at the Port} of Rotterdam. The Port of Rotterdam experiences alongshore currents of up to 2 knots, which are mainly tidal but also driven by winds, terrestrial outflow, and some larger-scale circulation in the North Sea (Van Heteren [7]). WERA phased-array radars have been installed at each side of the port to map surface currents in the critical area for shipping. A typical map is shown in Figure 11.

A new data management system as described in the next section provides easy and fast access to all archived current, wave, and wind data. The data are stored in an archive and can be accessed as time series plots for individual grid cells or as animated maps for the entire measured area. For each grid cell all data are marked with quality flags which can be used to exclude suspicious data from the analysis. Various output formats are available to compare the ocean radar data with data acquired from other sensors or numerical models (Schroevers et al. [23]).

6.2. Data Management System Structure. The new WERA data management system uses a MySQL database to store measured data. MySQL is a very powerful open-source relational database management system (RDMS) and allows subsequent tools in the WERA system to have a structured base from which data can be retrieved and stored. Using a database, in comparison with having data stored in text files, brings several benefits; some of them are as follows:

(i) Data can be stored in binary form, not in ASCII characters, reducing space requirements.

(ii) RDMS allows setting indexes, foreign keys, queries from simultaneous users, and other benefits which 


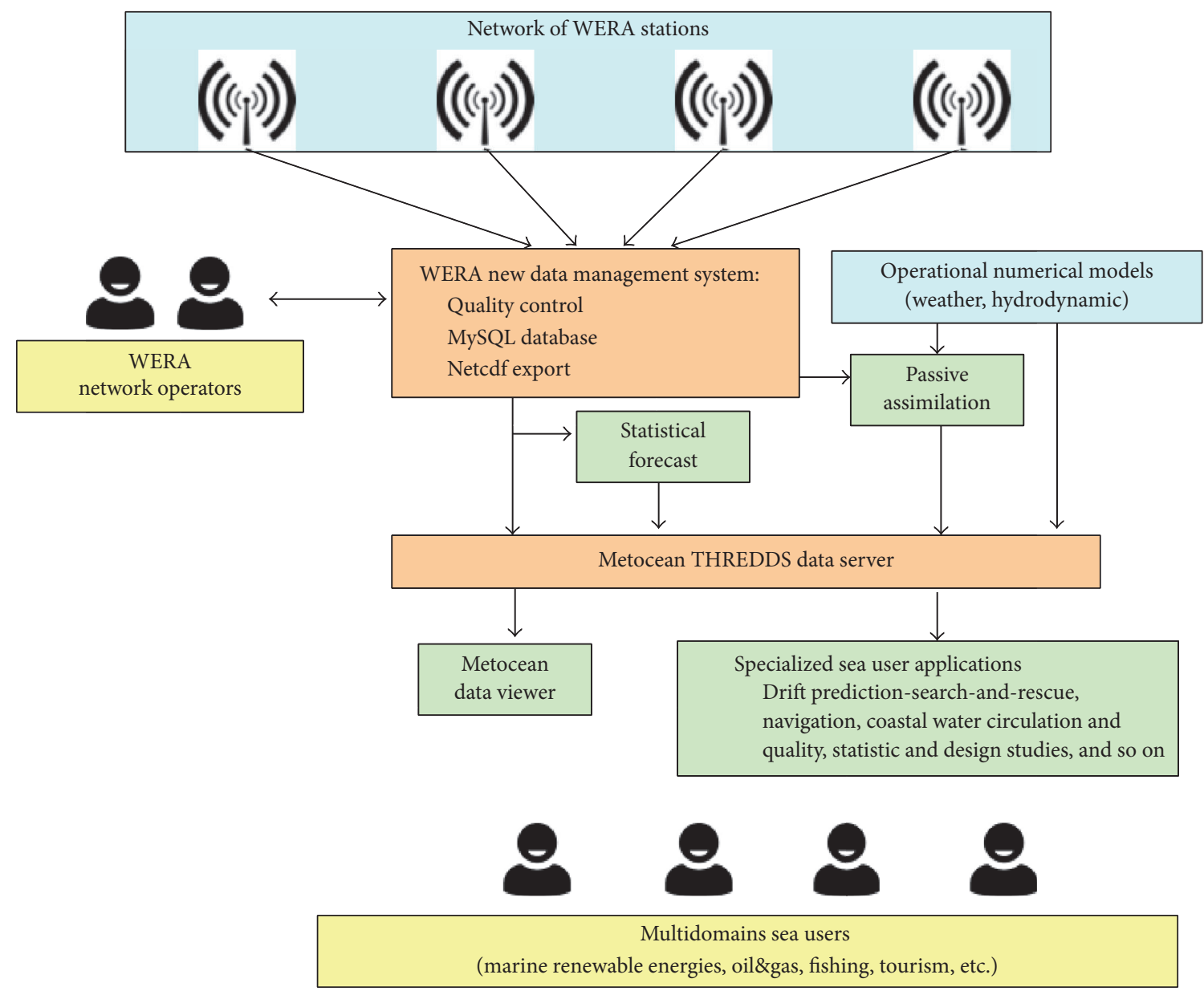

FIgURE 12: Example of data flow from the WERA stations to the end users using as center elements the WERA Data Management System and a Metocean TDS system.

allow a faster, ordered, and secure way of storing and retrieving data.

(iii) RDMS use the standard and widely known SQL code. This allows users of WERA systems to develop their own routines or modify the existing structure of the database to satisfy particular needs.

(iv) WERA users can access other types of open-source software (e.g., phpMyAdmin for MySQL databases).

The WERA data management system includes several software tools which process and store the oceanographic data measured by reading the data files provided by WERA and storing the information to the database in an organized manner using SQL commands as summarised in Figure 12. In standard configuration, these tools are executed automatically without any human intervention.

Additionally, the data management system includes a user-friendly web application that allows access to all the data stored in the database (please refer to Figure 2), as well as creating time series and exporting the data to different formats.
The relatively easy access to the data provided by the database can be readily exploited to implement the raft of hazard reduction applications in coastal zones.

\section{Conclusion}

Phased-array HF ocean radars have the capability to monitor the ocean surface far beyond the horizon because of the accuracy, resolution, and capacity to apply quality control flags to individual data points. The real-time tracking and forecast tracking of surface drifters are a leading feature of this radar technology and examples show that they can be tracked for up to 4 days with a spatial error of typically $2-4 \mathrm{~km}$ per day. The economic advantage of this in emergency searchand-rescue is significant and the application of Lagrangian tracking to coastal operations like dredging and construction reduces risks and hazards to the environment and other marine users.

The capability of phased-array HF radars to observe tsunami signatures in deeper waters adjacent to the continental shelf provides a useful element in assessing the impact of an approaching tsunami. The integration of radar data into an operational tsunami warning system is demonstrated by 
the case study of the operational Tsunami Warning Center in Oman. The radar measurements can be used to confirm the timing and magnitude of the tsunami following prewarning from the seismic and buoy elements of the system. Based on actual (not simulated) tsunami measurements a set of requirements for the WERA ocean radar have been developed to enable its integration into the TEWS system. The requirements include a high range resolution, a narrow beam directivity of antennas, and a fast data update mode to provide a possibility of tsunami detection in real time.

Routine real-time maps of wind directions from phasedarray HF radars in Australia can be used to identify the position and movement of meteorological fronts over the southern ocean. In the spring and summer the abrupt wind changes exacerbate the hazard of bush fires in the southeastern states, and accurate forecasting assists in the hazard reduction efforts.

An example of phased-array HF radar integrated into a port management system is given for the Port of Rotterdam in the Netherlands. Real-time, quality controlled data provide for the outer port area to reduce hazards of alongshore currents at the exit point of the sheltered channel as ships move in and out of the busy port. In general for coastal ports phased-array HF radars have potential for multipurpose hazard reduction. In this paper we have shown in separate case studies the various capabilities. The need for hazard reduction is brought to a focus in port areas where an HF radar can be used as a routine navigation aid (e.g., ship movements), for development work (e.g., dredging), searchand-rescue and pollution management (Lagrangian drifter tracking), and meteorological support (wind directions and wave heights) and serve as an element in a tsunami warning system. An explicit case where all of these features, except the last, would have combined to reduce the economic, environmental, and social burden is that of the MV Rena which went aground in the outer area of the Port of Tauranga in New Zealand on 5 October 2011, broke up, and eventually sank on 4 April 2012. She was a 52,000 tonnes vessel bunkered with 1,800 tonnes of oil and carrying 1,368 containers. About 850 tonnes of debris were removed from the sea during the 6-month period. Freely drifting containers, leaked oil, and salvage difficulties created the greatest hazards. The case study of the MV Rena supports the concept that every coastal port would be well-served by a phased-array HF radar system.

\section{Competing Interests}

The authors declare that they have no competing interests.

\section{Acknowledgments}

Archived data were sourced from Rijkswaterstaat, Netherlands, and the Integrated Marine Observing System (IMOS), Australia. IMOS is a national collaborative research infrastructure, supported by Australian Government. It is led by University of Tasmania in partnership with the Australian marine and climate science community. Helzel Messtechnik $\mathrm{GmbH}$ is the manufacturer of the WERA radar systems. gempa $\mathrm{GmbH}$ developed the Tsunami Observation and Simulation Terminal (TOAST) system.

\section{References}

[1] L. K. Shay, H. C. Graber, D. B. Ross, and R. D. Chapman, "Mesoscale ocean surface current structure detected by highfrequency radar," Journal of Atmospheric and Oceanic Technology, vol. 12, no. 4, pp. 881-900, 1995.

[2] Y. Mao and J. L. Luick, "Circulation in the southern Great Barrier Reef studied through an integration of multiple remote sensing and in situ measurements," Journal of Geophysical Research: Oceans, vol. 119, no. 3, pp. 1621-1643, 2014.

[3] R. H. Stewart and J. W. Joy, "HF radio measurements of surface currents," Deep-Sea Research and Oceanographic Abstracts, vol. 21, no. 12, pp. 1039-1049, 1974.

[4] H.-H. Essen, K.-W. Gurgel, and T. Schlick, "Measurement of ocean wave height and direction by means of HF radar: an empirical approach," Deutsche Hydrografische Zeitschrift, vol. 51, no. 4, pp. 369-383, 1999.

[5] A. Mantovanelli, M. L. Heron, A. Prytz, C. R. Steinberg, and D. Wisdom, "Validation of radar-based Lagrangian trajectories against surface-drogued drifters in the Coral Sea, Australia," in Proceedings of the IEEE OCEANS '11 MTS/IEEE Kona, Waikoloa, Hawaii, USA, September 2011.

[6] M. Heron, A. Dzvonkovskaya, and T. Helzel, "HF radar optimised for tsunami monitoring," in Proceedings of the MTS/IEEE OCEANS, IEEE, Genova, Italy, May 2015.

[7] D. M. Van Heteren, A. Schaap, and H. C. Peters, "Rijkwaterstaat's interest in HF radar," IEEE Journal of Oceanic Engineering, pp. 235-240, 1986.

[8] K.-W. Gurgel, Y. Barbin, and T. Schlick, "Radio frequency interference suppression techniques in FMCW modulated HF radars," in Proceedings of the IEEE OCEANS Conference, pp. 538-541, Aberdeen, UK, June 2007.

[9] M. L. Heron and A. Prytz, "The data archive for the phased array HF radars in the Australian coastal ocean radar network," in Proceedings of the IEEE OCEANS 2011, Santander, Spain, June 2011.

[10] R. Gomez, T. Helzel, C. R. Merz et al., "Real-time quality control of current velocity data on individual grid cells in WERA HF radar," in Proceedings of the OCEANS MTS/IEEE Conference, Taipei, Taiwan, April 2014.

[11] C. Ohlmann, P. White, L. Washburn, E. Terrill, B. Emery, and M. Otero, "Interpretation of coastal HF radar-derived surface currents with high-resolution drifter data," Journal of Atmospheric and Oceanic Technology, vol. 24, no. 4, pp. 666680, 2007.

[12] D. S. Ullman, J. O’Donnell, J. Kohut, T. Fake, and A. Allen, “Trajectory prediction using HF radar surface currents: Monte Carlo simulations of prediction uncertainties," Journal of Geophysical Research, vol. 111, no. 12, 2006.

[13] A. Mantovanelli, M. L. Heron, S. F. Heron, and C. R. Steinberg, "Relative dispersion of surface drifters in a barrier reef region," Journal of Geophysical Research: Oceans, vol. 117, no. 11, Article ID C11016, 2012.

[14] S. C. Shadden, F. Lekien, and J. E. Marsden, "Definition and properties of Lagrangian coherent structures from finitetime Lyapunov exponents in two-dimensional aperiodic flows," Physica D: Nonlinear Phenomena, vol. 212, no. 3-4, pp. 271-304, 2005. 
[15] T. Helzel, V. Marriette, and M. Pavec, "Coastal radar WERA: a tool for harbour management," European Journal of Navigation, vol. 8, no. 1, 2010.

[16] G. Green, "On the motion of waves in a variable canal of small depth and width," Transactions of the Cambridge Philosophical Society, vol. 6, pp. 457-462, 1838.

[17] B. Kinsman, Wind Waves, Prentice-Hall, Englewood Cliffs, NJ, USA, 1965.

[18] K.-W. Gurgel, A. Dzvonkovskaya, T. Pohlmann, T. Schlick, and E. Gill, "Simulation and detection of tsunami signatures in ocean surface currents measured by HF radar," Ocean Dynamics, vol. 61, no. 10, pp. 1495-1507, 2011.

[19] W. Hanka, J. Saul, B. Weber, J. Becker, and P. Harjadi, "Realtime earthquake monitoring for tsunami warning in the Indian Ocean and beyond," Natural Hazards and Earth System Science, vol. 10, no. 12, pp. 2611-2622, 2010.

[20] M. L. Heron and R. J. Rose, "On the application of HF ocean radar to the observation of temporal and spatial changes in wind direction," IEEE Journal of Oceanic Engineering, vol. OE-11, no. 2, pp. 210-218, 1986.

[21] L. R. Wyatt, L. J. Ledgard, and C. W. Anderson, "Maximum likelihood estimation of the directional distribution of $0.53 \mathrm{~Hz}$ ocean waves," Journal of Atmospheric and Oceanic Technology, vol. 14, no. 3, pp. 591-603, 1997.

[22] L. R. Wyatt, "Shortwave direction and spreading measured with HF radar," Journal of Atmospheric \& Oceanic Technology, vol. 29, no. 2, pp. 286-299, 2012.

[23] M. Schroevers, M. Verlaan, F. Zijl, P. Verburgh, and F. Buschman, "Navigation information for the Rotterdam Harbour by assimilating HF radar in a 3D model," in Proceedings of the 11th IEEE/OES Current, Waves and Turbulence Measurement (CWTM '15), pp. 1-3, IEEE, St. Petersburg, Fla, USA, March 2015. 


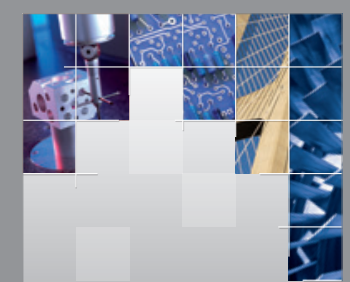

\section{Enfincering}
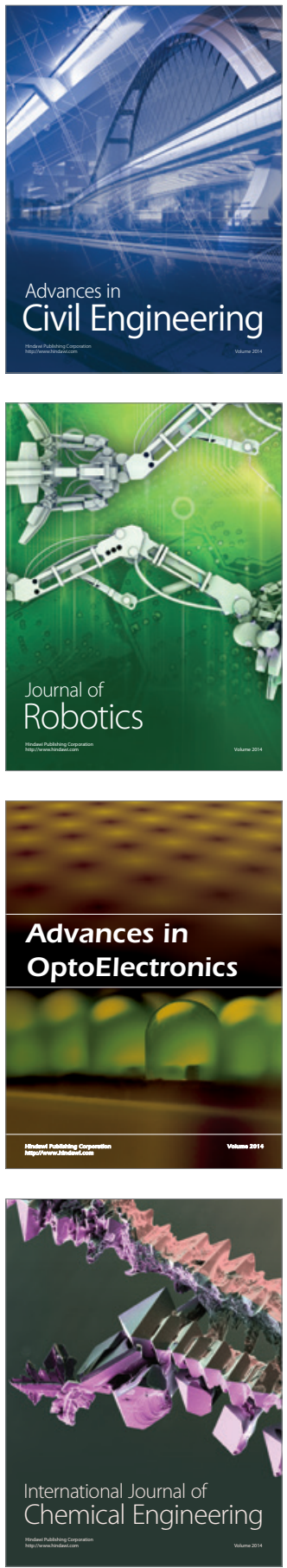

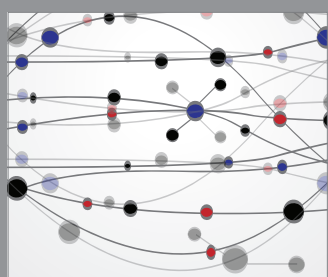

The Scientific World Journal

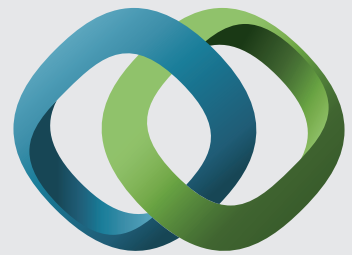

\section{Hindawi}

Submit your manuscripts at

http://www.hindawi.com
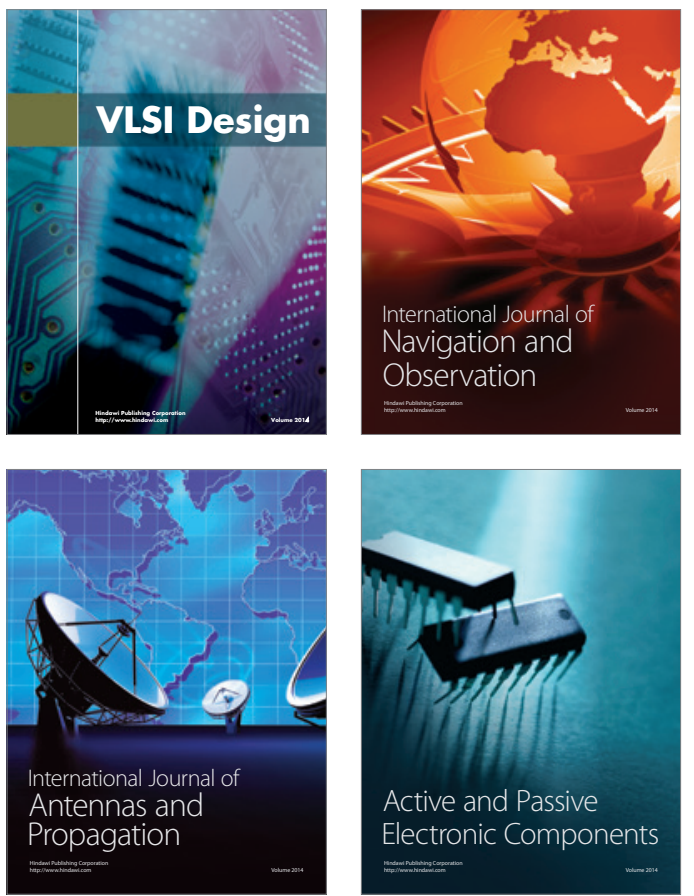
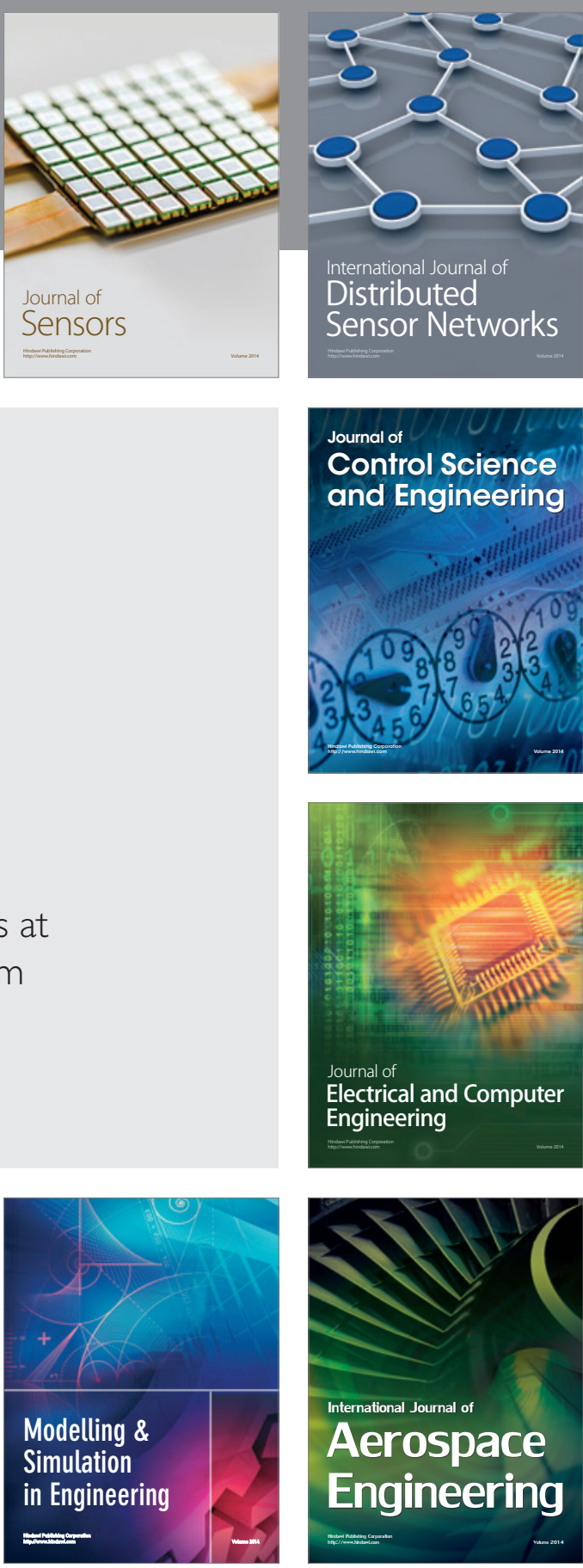

International Journal of

Distributed

Sensor Networks

Journal of

Control Science

and Engineering
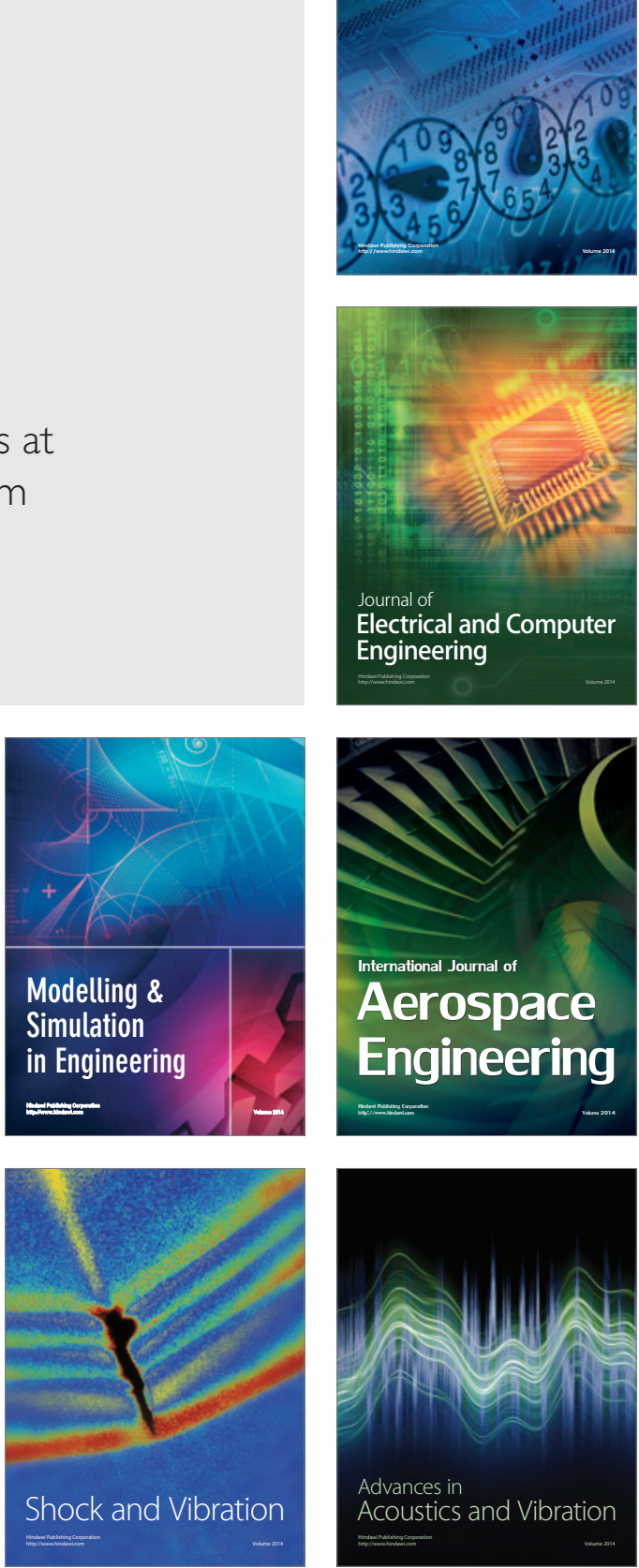